\title{
Male achromatic wing colouration is related to body condition and female reproductive investment in a dichromatic species, the upland goose
}

\author{
Anja Gladbach • David Joachim Gladbach • \\ Petra Quillfeldt
}

Received: 12 August 2010/ Accepted: 7 November 2010/Published online: 14 December 2010

(C) The Author(s) 2010. This article is published with open access at Springerlink.com

\begin{abstract}
In many bird species, achromatic plumage patch size can serve as a male status signal, but the use of variations in the achromatic colours themselves as a quality signal has only recently come into focus. In our study, we sought to determine whether achromatic plumage reflects individual quality in the upland goose (Chloephaga picta leucoptera). We examined the relationship between male head and wing reflectance, male condition and female reproductive investment. We found that males with darker specula and greater contrast between the white wing coverts and the speculum were in a better body condition. Variations in the brightness of the white plumage were not a quality signal in the upland goose. The information gleaned from the wing colouration of male upland geese could be used during mate selection, when females choose their mate on the basis of the outcomes of aggressive encounters. During these fights, the males expose their white coverts and their specula, which are normally tucked beneath body feathers.
\end{abstract}

Keywords Upland goose - Chloephaga picta leucoptera . Male colouration · Individual quality · Achromatic colour . Speculum

Electronic supplementary material The online version of this article (doi:10.1007/s10164-010-0247-8) contains supplementary material, which is available to authorized users.

A. Gladbach $(\bowtie) \cdot$ P. Quillfeldt

Max Planck Institute for Ornithology, Vogelwarte Radolfzell, Schlossallee 2, 78315 Radolfzell, Germany

e-mail: anja.gladbach@gmx.de

D. J. Gladbach

Agroecology, Department of Crop Science,

University of Göttingen, Waldweg 26,

37073 Göttingen, Germany

\section{Introduction}

In many species, females prefer to mate with males with the most elaborate ornaments (Andersson 1994), as those traits can indicate aspects of male quality (Zahavi 1975; KodricBrown and Brown 1984). In birds, many studies have found plumage colouration to be correlated to different male quality characteristics, like condition (e.g. Keyser and Hill 1999; Peters et al. 2007), territory quality (e.g. Keyser and Hill 2000), parasite load (e.g. Hõrak et al. 2001), immune function (e.g. Maney et al. 2008) or parental effort (e.g. Keyser and Hill 2000; Siefferman and Hill 2003).

Achromatic plumage colouration (black, grey and white) has been studied before, with the main focus being the patch size of achromatic plumage, including its relation to reproductive investment, individual quality and status signalling (e.g. Moller 1987; Part and Qvarnstrom 1997; e.g. Doucet et al. 2005; Hanssen et al. 2006; Hanssen et al. 2008). Characteristics of the achromatic colour itself (like brightness and chroma) as a quality signal have only come into focus quite recently (e.g. Mennill et al. 2003; Woodcock et al. 2005; Hanssen et al. 2009), although there has been evidence from observations and experiments that female choice may be influenced by variation in achromatic colour (e.g. Saetre et al. 1994). For example, in male black-capped chickadees Poecile atricapillus, reproductive success was predicted by the reflectance of achromatic plumage (Doucet et al. 2005), and in the ostrich Struthio camelus, male white colouration was found to be related to male immune capacity (a measurement of male quality), and both black and white colouration to egg mass, indicating that females adjust their investment according to their perception of male quality (Bonato et al. 2009a, b).

In our study we sought to determine whether achromatic plumage characteristics reflect individual quality in the 
upland goose Chloephaga picta leucoptera. Upland geese belong to the order of the sheldgeese (Tadornini), a group that resembles true geese and shows similar habits but is more closely related to shelducks and ducks. One of the most interesting aspects of the closely knit group of the genus Chloephaga is the great variation in colouration between the species and sexes, ranging from nearly no dimorphism in the Andean goose C. melanoptera (both sexes are mainly white), the ruddy-headed goose C. rubidiceps and the ashy-headed goose $C$. poliocephala (both have mainly brown plumage), to the kelp goose C. hybrida and the upland goose, which exhibit very strong sexual dimorphism, with males being mainly white and females brown (Summers and McAdam 1993). While this dimorphism is still restricted to the plumage in kelp geese, it even extends to the integument colouration in upland geese (males: black tarsus, females: yellow-orange tarsus). Besides this, males and females share some wing characteristics, namely white upper wing coverts, a metalliccoloured speculum formed by the secondary coverts (rather than by the secondaries, as in other anatines), and white secondaries. There is still speculation about the causes of the differences in white colouration in this group, with one possibility being that it evolved in order to be conspicuous (Summers and McAdam 1993). Especially kelp and upland geese are very aggressive birds, defending large territories and signalling their ownership with erect posturing. A plumage colouration that contrasts as much as possible with the background would thus be advantageous. In females, the need to be cryptic during incubation could have preserved the brown plumage. However, this theory cannot explain the white plumage in female Andean geese. Upland geese are highly territorial and socially monogamous, usually returning to the same territory with the same mate every year (Summers and McAdam 1993). Male upland geese invest heavily in the establishment and defence of their breeding territory. They increase their aggressive activities gradually during the season. Besides evicting their own young from the previous breeding season, the territory has to be defended against intruding pairs looking for a breeding place, and territorial boundaries with neighbouring pairs need to be maintained throughout the breeding season (Summers and McAdam 1993). Aggressive encounters range from pacing side by side along the territorial boundaries, the exposure of their carpal knobs, to gripping each other by the neck and dashing their wings against each other. When attacking another bird, the male runs rapidly over the ground with its head low and his folded wings slightly spread, thus exposing his white upper coverts and his speculum, which are both normally hidden when the wing is closed [Electronic supplementary material (ESM), Fig. S1].
White plumage may be used in signalling in different ways: either as a quality signal itself or as a contrast to coloured plumage parts. Despite being inexpensive to produce, as the feathers contain no costly pigments, white plumage may serve as a quality signal, with costs arising from its maintenance and the fact that feather quality is more visible (Fitzpatrick 1998). Depigmented feathers have been found to wear faster in birds with lower feather quality, thereby indicating a birds' ability to invest in highquality feathers (e.g. Kose and Moller 1999). Additionally, the contrast of the white with the background or dark plumage parts may be an important signal, as it can improve the perception of displays or the signaller itself (Galvan 2008). To investigate whether white plumage may serve as a signal of quality in male upland geese, we examined the relationship between achromatic plumage reflectance, male condition, and female reproductive investment. Additionally, we compared the possible signalling function of wing colouration between males and females.

\section{Study area}

The study was carried out in the New Island Nature Reserve, Falkland Islands $\left(51^{\circ} 43^{\prime} \mathrm{S}, 61^{\circ} 17^{\prime} \mathrm{W}\right)$, from October to December in 2007 and 2008. New Island was established as a nature reserve in 1973, when all livestock were removed from the island. This led to an increase in the density of upland geese on this island, making it one of the most densely populated of the Falkland Islands (Quillfeldt et al. 2005).

\section{Materials and methods}

The basic breeding biology and life cycle of upland geese was studied in the Falklands from 1977 to 1980 (Summers 1983a). Take-up of territories starts in August, and egg laying occurs in late September, with most clutches being laid by the end of October. Hatching mainly takes place between mid-October and mid-November, and fledging starts at approximately 70 days of age.

At the beginning of each field season, the nests were mapped. Numbers of eggs per nest were counted, length and breadth of eggs were measured to the nearest $0.1 \mathrm{~mm}$ using calipers, and weight was recorded to the nearest $0.1 \mathrm{~g}$ using a digital balance. Egg volume $(V)$ was determined from egg length $L$ (in $\mathrm{cm}$ ) and egg breadth $B$ (in $\mathrm{cm}$ ) as $V=\left(L \times B^{2} \times 0.507\right)$, according to Furness and Furness (1981). Total volume of the clutch was determined by summing the individual volumes of all eggs in each clutch. 
We caught adults during the period when they attended their brood using a $3 \times 5 \mathrm{~m}$ whoosh net. One person herded the family of geese slowly to the catching area, and when they arrived directly in front of the furled net, the other researcher pulled the trigger. Adults were marked with individual metal rings and weighed to the nearest $10 \mathrm{~g}$ using a digital spring balance. Head length, culmen length, and tarsus length were measured to the nearest $0.1 \mathrm{~mm}$ using callipers; wing length (maximum flattened chord) was measured to the nearest $1 \mathrm{~mm}$ using a stopped rule. A principal components analysis (PCA) extracted one principal component (PC1) from wing, head, bill and tarsus measurements as an overall measure of body size in both males and females. In females, PC1 (with an eigenvalue of 1.794) explained $44.844 \%$ of the variance. In males, PC1 (with an eigenvalue of 2.001) explained $50.018 \%$ of the variance. The body condition for males and females was determined while accounting for structural size, based on a regression of body mass on $\mathrm{PC} 1$. Body condition was expressed as the ratio of the observed body mass to the derived expected body mass, according to individual size.

\section{Spectrophotometric colour measurements}

Reflectance spectra between 300 and $700 \mathrm{~nm}$ were recorded using an AvaSpec-2048 fibre optic spectrometer (Avantes, Eerbeek, The Netherlands) with an AvaLight-DHc deuterium/ halogen light source unit, and FCR-7UV400 reflection probe fibre optics. We took five readings each from the white head, the white wing coverts and the speculum on each male. As each trait appeared uniform in colour, it was measured in randomly allocated places, moving the probe at least $2 \mathrm{~cm}$ between measurements. We used the average reflectance curve from the five readings for each region in the following analyses. Reflection was recorded using a probe held normal to the surface, collecting light from a spot $4.5 \mathrm{~mm}$ in diameter. The measurements were taken outside with the probe held directly against the feather surface, so that no ambient light would affect the measurements. A white reference (WS-2 white reference tile for reflectance measurements, Avantes) and a dark reference (measured with the lights turned off) were taken for calibration purposes before each individual was measured.

Spectrometric data were analysed using AVICOL v.3 (Gomez 2006). Brightness was calculated as the mean reflectance between 300 and $700 \mathrm{~nm}$. To describe the contrast between the white wing coverts and the speculum, we calculated the contrast as the ratio of the mean brightness values (\% reflectance) of the wing coverts to the speculum. We also measured aspects of the UV colouration of the speculum (UV brightness, UV chroma and maximum reflectance between 350 and $450 \mathrm{~nm}$ ). UV brightness was highly correlated with the overall brightness of the speculum ( $r=0.961, P<0.001$ ), as were UV contrast and overall contrast $(r=0.947, P<0.001)$.

Statistical analysis

Statistical tests were performed in SPSS 11.0. Means are given with standard errors. The significance level was set to $P<0.05$. Normality was tested using KolmogorovSmirnov tests. We assessed significance with Pearson correlations and analysis of variance (ANOVA). We captured and measured 32 females and 34 males in 2007 and 46 females and 35 males in 2008, of which 20 females and 10 males were measured in both seasons. We found no differences between the study years in both males and females in all measured parameters (all $P>0.200$ ). We therefore decided to pool all data in the subsequent analyses and use the first measurement of each animal to avoid pseudoreplication. Note that sample sizes may differ because of missing values. Some territories were not visited before the chicks had hatched, and hence data on clutch size and egg volumes are missing.

\section{Results}

\section{Differences between the sexes}

Females had brighter white wing coverts than males (Table 1), but we found no sex differences in the brightness of the speculum, speculum UV characteristics, and in the contrast between wing coverts and the speculum (Table 1).

\section{Colouration and body condition}

Body condition was higher in males with lower brightness values of the speculum ( $r=-0.37, N=55, P=0.006$; Table 2; Fig. 1a) and lower UV brightness of the speculum ( $r=-0.31, N=55, P=0.020)$, but it was unrelated to the brightness of the head and the wing coverts (Table 1). We found that the contrast between the wing coverts and the speculum (brightness of wing coverts/brightness of speculum) was significantly related to body condition, with males that had higher ratios (i.e. darker specula compared to wing coverts) being in better body condition ( $r=0.48$, $N=55, P<0.001$; Table 2; Fig. 1b). In females, we found no significant relation between wing colouration and body condition (all $P>0.1$ ).

Colouration and reproductive parameters

In males, the average brightness of the speculum was negatively related to clutch volume, with individuals with a darker speculum being mated to females that laid larger 
Table 1 Mean reflectance values (\%) of wing coverts and the speculum, UV chroma and UV peak of the speculum, and mean contrast between wing coverts and the speculum of upland geese in the wild

\begin{tabular}{|c|c|c|c|c|c|c|c|}
\hline & \multicolumn{3}{|l|}{ Males } & \multicolumn{3}{|l|}{ Females } & \multirow[t]{2}{*}{ Test } \\
\hline & Mean + SE & Range & $n$ & Mean + SE & Range & $n$ & \\
\hline Wing coverts & $98.24 \pm 1.34$ & $69.51-120.38$ & 55 & $103.05 \pm 1.31$ & $103.05-1.31$ & 60 & $F_{1,114}=6.558, \boldsymbol{P}=\mathbf{0 . 0 1 2}$ \\
\hline Speculum & $13.66 \pm 0.46$ & $6.65-22.35$ & 55 & $13.43 \pm 0.48$ & $7.78-25.56$ & 60 & $F_{1,114}=0.116, P=0.734$ \\
\hline Speculum UV brightness & $12.67 \pm 0.45$ & $5.59-20.45$ & 55 & $12.83 \pm 0.45$ & $6.84-24.57$ & 60 & $F_{1,114}=0.063, P=0.802$ \\
\hline Speculum UV chroma & $0.23 \pm 0.01$ & $0.19-0.27$ & 55 & $0.24 \pm 0.01$ & $0.19-0.26$ & 60 & $F_{1,114}=0.326, P=0.569$ \\
\hline Speculum UV peak & $406.76 \pm 3.64$ & $351-450$ & 55 & $405.76 \pm 3.73$ & $350-450$ & 60 & $F_{1,114}=0.036, P=0.849$ \\
\hline $\begin{array}{l}\text { Contrast between wing } \\
\text { coverts and speculum }\end{array}$ & $7.58 \pm 0.24$ & $4.27-12.16$ & 55 & $8.18 \pm 0.28$ & $4.00-14.39$ & 60 & $F_{1,114}=2.691, P=0.104$ \\
\hline
\end{tabular}

We tested for differences between the sexes using analysis of variance (ANOVA). Significant value is stated in bold

Table 2 Relationships between the brightnesses of different plumage regions and body condition, clutch and mean egg volume in male upland geese on New Island

\begin{tabular}{llll}
\hline Body region & $\begin{array}{l}\text { Body } \\
\text { condition }\end{array}$ & $\begin{array}{l}\text { Clutch } \\
\text { volume }\end{array}$ & $\begin{array}{l}\text { Mean egg } \\
\text { volume }\end{array}$ \\
\hline Head & 0 & 0 & 0 \\
Wing coverts & 0 & 0 & 0 \\
$\begin{array}{l}\text { Speculum } \\
\begin{array}{l}\text { Contrast between wing } \\
\text { coverts and speculum }\end{array}\end{array}$ & - & - & 0 \\
\hline
\end{tabular}

Pearson correlations: "0": no significant effect (i.e. $P>0.05$ ), "+" positive relationship (i.e. increase or decrease together), "-" negative relationship (i.e. one increases while the other decreases)

a The positive relation between clutch volume and speculum was no longer significant at the 0.05 level after controlling for hatching date. There were no significant relationships in females. See the "Results" section for statistics

clutches (Pearson correlation: brightness: $r=-0.41$, $N=24, P=0.049$; Table 1; Fig. 2, UV brightness: $r=$ $-0.44, N=24, P=0.039)$. As there is a seasonal trend (with clutch volume being higher in earlier clutches; Gladbach et al. 2010b), we ran a second analysis controlling for hatching date (partial correlation: brightness: $r=-0.326, \quad N=24, P=0.129$; UV brightness: $r=$ $-0.30, N=24, P=0.159)$. The mean egg volume was unrelated to male colouration. There was no significant relationship of wing colouration to clutch volume or mean egg volume in females, although brightness of the speculum showed a tendency to be negatively related to clutch volume $(r=-0.290, N=23, P=0.180)$.

\section{Discussion}

Our findings demonstrate that in upland geese, male achromatic plumage reflectance predicts body condition in males and investment in clutch volume by their pair

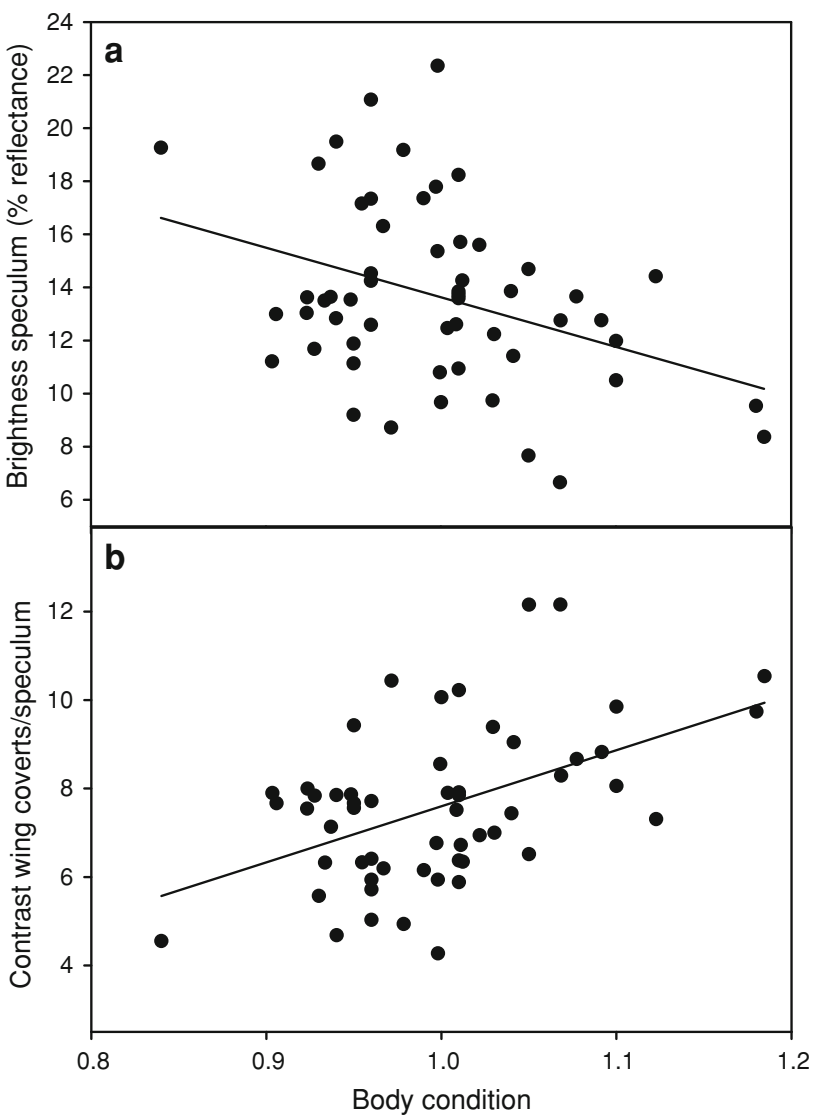

Fig. 1 Relationship between brightness of the speculum and body condition (a) and relationship between and body condition and contrast between wing coverts and speculum (b) in male Upland geese measured on New Island. See text for statistical analysis

partners. In particular, we found that males with darker specula and a greater contrast between their white wing coverts and their specula had better body conditions. Females mated to males with darker specula laid clutches with bigger volumes. We could not support the hypothesis that variations in the brightness of the white plumage itself 


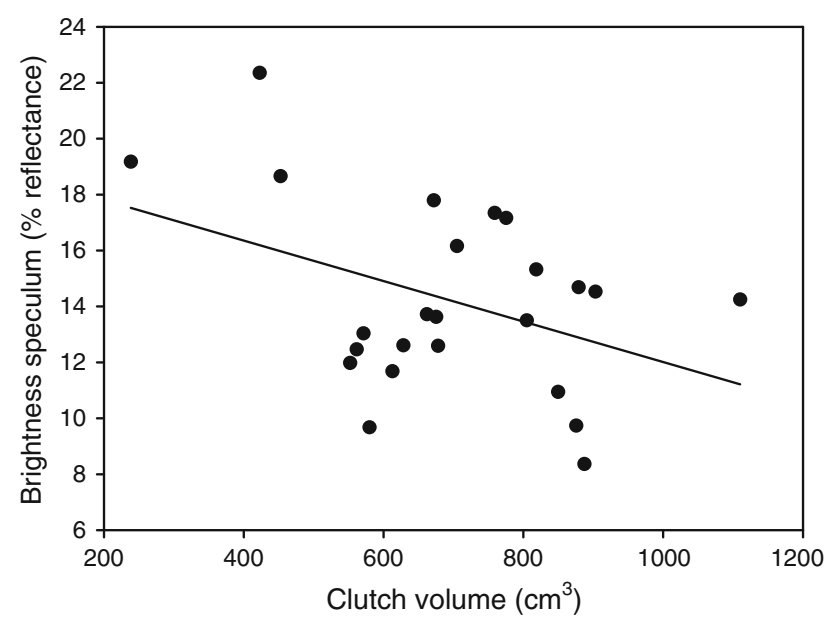

Fig. 2 Relationship between brightness of the speculum of male upland geese and the clutch volume laid by their partner on New Island. See text for statistical analysis

are a quality signal in the upland goose. Males and females only differed in the brightness of their wing coverts, which may be explained by the greater wear of these feathers in males where they are exposed during fights, which is not the case for females. We also found no relation of most of the UV parameters of the speculum to either body condition or reproductive parameters in males and females. Only the UV brightness of the speculum in males was related to body condition, but as UV brightness and overall brightness were highly correlated, we would be cautious to interpret this finding as UV signalling.

The information content of the wing colouration of male upland geese could be used during mate choice. During pair formation, females incite males to attack other males or females, and then select their mate on the basis of the outcome of these aggressive encounters (Johnsgard 1965). The male responds to female incitation by adopting an erect posture, holding the carpal joints of the wings out from the body, thereby exposing the white coverts and the speculum, which are normally tucked beneath body feathers (ESM Fig. S1). Avian wing displays can signal aggressiveness or willingness to escalate fights (Hurd and Enquist 2001), and the white coverts and the speculum in the upland goose may function as "coverable badges" (Hansen and Rohwer 1986) that are only exposed when birds are highly motivated to fight but are hidden when the birds are not willing to engage in an aggressive encounter. Differences in male wing colouration may serve as an indicator of status or condition, and reduce the need for costly aggressive interactions. Based upon our results, it can be speculated that not only the outcome of the aggressive encounters but also aspects of plumage quality may influence female choice in the upland goose.

Contrasts between adjacent plumage regions have been found to be an important aspect of achromatic plumage in some other studies (Mennill et al. 2003; Bokony et al. 2006; Bonato et al. 2009a). For example, Bokony et al. (2006) could show that in male house sparrows (Passer domesticus), the conspicuousness of wingbars may increase the defence success of their bearer in aggressive interactions. Measurements of male plumage characteristics during the time of pair formation and their relation to lost/won fights could further highlight the role of such signals in the upland goose. To our knowledge, there have been no studies so far on the signalling ability of the iridescent speculum found in the Anatidae. Iridescent colours change in appearance with the angle of observation or illumination, so results from spectrophotometric measurements of iridescent plumage can be very sensitive to changes in the measurement geometry (e.g. Cuthill et al. 1999; Santos et al. 2007; Maia et al. 2009), which influence both the hue and the chroma of a colour. As we were not able to guarantee exactly the same measurement geometry under fieldwork conditions, we decided to only include speculum brightness as one aspect of colouration in our study. Birds in good body condition could be more tolerant to stressful situations, or both a good body condition and speculum characteristics could indicate good genetic quality. This is supported by Gladbach et al. (2010c), who found that the $H / L$ ratio (a common measure of stress in birds) is related to body condition in male upland geese, with males in poor body condition showing higher stress measures. The higher body conditions of males with darker specula could also be linked to a condition dependency of the feather moult. Skipping the moult of the primaries for up to three consecutive years has been reported in upland geese before (Summers 1983b), and the gradual impairment of flight feathers might be unimportant to this nonmigratory species. Skipping the moult could have the advantage of saving energy and nutrients, and the colour of the speculum feathers may then be subject to degradation, leading to a paler colour of the older feathers of males in poor body condition. A study sampling feathers from the speculum and spectrophotometric measurements performed under standard laboratory conditions could further highlight the signalling aspect of speculum colouration.

The relationship of male wing colouration to female reproductive investment could be caused by high-quality males in good body condition gaining access to or being able to defend high-quality territories, thereby providing the basis for a high investment in clutch size by their female. However, as the relationship was no longer significant after controlling for hatching date, a study using a larger data set is needed to clarify whether the relationship between clutch volume and male colouration can be verified. While reproductive parameters like egg size seem to be related to the inherent quality of a female in upland geese, clutch size appears to be flexible and to vary 
according to the current conditions (Gladbach et al. 2010b). Additionally, Gladbach et al. (2010a) found that in upland geese, females with more orange-coloured legs and more red-like head colours had higher clutch and egg volumes than females with paler leg and head colouration, and a more reddish plumage colouration was related to a higher body condition. Thus, in females, these aspects of plumage and integument colouration may be used as quality signals rather than the speculum. As upland geese form long-term pair bonds, a study comparing clutch data, male wing colouration and territory quality in different years is now necessary to understand the relationship of male colouration to female investment.

In summary, we found that, contrary to our expectations, the brightness of the speculum rather than the white plumage was an indicator of condition in male upland geese. In contrast, wing colouration was not related to condition parameters in females. Further studies should now concentrate on other spectrophotometric colour parameters of the iridescent speculum to gain more knowledge about its signalling ability in upland geese as well as in other Anatidae where this special wing characteristic occurs.

Acknowledgments We are grateful to the New Island Conservation Trust for allowing us to carry out this study on the island and for providing accommodation and transport. We would like to thank Riek van Noordwijk, Rafael Matias and Andreas Michalik for their help in capturing "difficult" goose families. Juan Masello helped with the setup of the spectrometer system. The manuscript benefited from the comments of two anonymous referees. This work would not have been possible without the support of Ian, Maria and Georgina Strange and Dan Birch. A.G. received financial support from the Bayerische Eliteförderung, the Arthur von Gwinner Foundation, the German Academic Exchange Service (DAAD), and the German Ornithological Society (DO-G). P.Q. was funded by DFG, Germany (Emmy Noether Programme, Qu148/1-3).

Open Access This article is distributed under the terms of the Creative Commons Attribution Noncommercial License which permits any noncommercial use, distribution, and reproduction in any medium, provided the original author(s) and source are credited.

\section{References}

Andersson MB (1994) Sexual selection. Princeton University Press, Princeton

Bokony V, Lendvai AZ, Liker A (2006) Multiple cues in status signalling: the role of wingbars in aggressive interactions of male house sparrows. Ethology 112:947-954

Bonato M, Evans MR, Cherry MI (2009a) Investment in eggs is influenced by male coloration in the ostrich, Struthio camelus. Anim Behav 77:1027-1032

Bonato M, Evans MR, Hasselquist D, Cherry MI (2009b) Male coloration reveals different components of immunocompetence in ostriches, Struthio camelus. Anim Behav 77:1033-1039
Cuthill IC, Bennett ATD, Partridge JC, Maier EJ (1999) Plumage reflectance and the objective assessment of avian sexual dichromatism. Am Nat 153:183-200

Doucet SM, Mennill DJ, Montgomerie R, Boag PT, Ratcliffe LM (2005) Achromatic plumage reflectance predicts reproductive success in male black-capped chickadees. Behav Ecol 16:218-222

Fitzpatrick S (1998) Birds' tails as signaling devices: markings, shape, length, and feather quality. Am Nat 151:157-173

Furness RW, Furness BL (1981) A technique for estimating the hatching dates of eggs of unknown laying date. Ibis 123:98-102

Galvan I (2008) The importance of white on black: unmelanized plumage proportion predicts display complexity in birds. Behav Ecol Sociobiol 63:303-311

Gladbach A, Gladbach D, Kempenaers B, Quillfeldt P (2010a) Female-specific colouration, carotenoids and reproductive investment in a dichromatic species, the upland goose Chloephaga picta leucoptera. Behav Ecol Sociobiol 64:1779-1789

Gladbach A, Gladbach D, Quillfeldt P (2010b) Seasonal clutch size decline and individual variation in the timing of breeding are related to female body condition in a non-migratory species, the Upland Goose Chloephaga picta leucoptera. J Ornithol 151:817-825

Gladbach A, Gladbach DJ, Quillfeldt P (2010c) Variations in leucocyte profiles and plasma biochemistry are related to different aspects of parental investment in male and female Upland geese Chloephaga picta leucoptera. Comp Biochem Physiol A Mol Integr Physiol 156:269-277

Gomez D (2006) AVICOL, a program to analyse spectrometric data. http://sites.google.com/site/avicolprogram/

Hansen AJ, Rohwer S (1986) Coverable badges and resource defense in birds. Anim Behav 34:69-76

Hanssen SA, Folstad I, Erikstad KE (2006) White plumage reflects individual quality in female eiders. Anim Behav 71:337-343

Hanssen SA, Hasselquist D, Folstad I, Erikstad KE (2008) A label of health: a previous immune challenge is reflected in the expression of a female plumage trait. Biol Lett 4:379-381

Hanssen SA, Bustnes JO, Tveraa T, Hasselquist D, Varpe O, Henden JA (2009) Individual quality and reproductive effort mirrored in white wing plumage in both sexes of south polar skuas. Behav Ecol 20:961-966

Hõrak P, Ots I, Vellau H, Spottiswoode C, Moller AP (2001) Carotenoidbased plumage coloration reflects hemoparasite infection and local survival in breeding great tits. Oecologia 126:166-173

Hurd PL, Enquist M (2001) Threat display in birds. Can J Zool Rev Can Zool 79:931-942

Johnsgard PA (1965) Handbook of waterfowl behaviour. Constable, London

Keyser AJ, Hill GE (1999) Condition-dependent variation in the blueultraviolet coloration of a structurally based plumage ornament. Proc R Soc Lond Ser B Biol Sci 266:771-777

Keyser AJ, Hill GE (2000) Structurally based plumage coloration is an honest signal of quality in male blue grosbeaks. Behav Ecol 11:202-209

Kodric-Brown A, Brown JH (1984) Truth in advertising - the kinds of traits favored by sexual selection. Am Nat 124:309-323

Kose M, Moller AP (1999) Sexual selection, feather breakage and parasites: the importance of white spots in the tail of the barn swallow (Hirundo rustica). Behav Ecol Sociobiol 45:430-436

Maia R, Caetano JVO, Bao SN, Macedo RH (2009) Iridescent structural colour production in male blue-black grassquit feather barbules: the role of keratin and melanin. J R Soc Interface 6:S203-S211

Maney DL, Davis AK, Goode CT, Reid A, Showalter C (2008) Carotenoid-based plumage coloration predicts leukocyte parameters during the breeding season in northern cardinals (Cardinalis cardinalis). Ethology 114:369-380 
Mennill DJ, Doucet SM, Montgomerie R, Ratcliffe LM (2003) Achromatic color variation in black-capped chickadees, Poecile atricapilla: black and white signals of sex and rank. Behav Ecol Sociobiol 53:350-357

Moller AP (1987) Variation in badge size in male House sparrows Passer domesticus - evidence for status signaling. Anim Behav 35:1637-1644

Part T, Qvarnstrom A (1997) Badge size in collared flycatchers predicts outcome of male competition over territories. Anim Behav 54:893-899

Peters A, Delhey K, Johnsen A, Kempenaers B (2007) The conditiondependent development of carotenoid-based and structural plumage in nestling blue tits: males and females differ. Am Nat 169:S122-S136

Quillfeldt P, Strange IJ, Masello JF (2005) Escape decisions of incubating females and sex ratio of juveniles in the Upland Goose Chloephaga picta. Ardea 93:171-178

Saetre GP, Dale S, Slagsvold T (1994) Female pied flycatchers prefer brightly colored males. Anim Behav 48:1407-1416
Santos S, Lumeij JT, Westers P, van Wandelen BBI (2007) Sexual dichromatism in the European Magpie Pica pica. Not as black and white as expected. Ardea 95:299-310

Siefferman L, Hill GE (2003) Structural and melanin coloration indicate parental effort and reproductive success in male eastern bluebirds. Behav Ecol 14:855-861

Summers RW (1983a) The life-cycle of the Upland goose (Chloephaga picta) in the Falkland Islands. Ibis 125:524-544

Summers RW (1983b) Molt-skipping by Upland geese (Chloephaga picta) in the Falkland Islands. Ibis 125:262-266

Summers RW, McAdam JH (1993) The Upland goose. Bluntisham Books, Huntingdon

Woodcock EA, Rathburn MK, Ratcliffe LM (2005) Achromatic plumage reflectance, social dominance and female mate preference in black-capped chickadees (Poecile atricapillus). Ethology 111:891-900

Zahavi A (1975) Mate selection-a selection for a handicap. J Theor Biol 53:205-214 